\title{
Formal Versus Informal Mentoring Of MAS Professionals
}

Philip H. Siegel, Augusta State University, USA

Todd Schultz, Augusta State University, USA

Sharon Landy, Augusta State University, USA

\begin{abstract}
CPA firms have consistently experienced high turnover and poor performance amongst their management advisory and information systems professionals. As Keller (2008) suggests, mentoring programs are a mechanism to help attract and maintain good employees. The extant accounting literature well documents the benefits of mentoring such as enhanced communication, greater organizational commitment, higher professional performance and reduced personnel turnover (Scandura \& Viator, 1994; Siegel \& Reintein, 2001; Siegel et al., 1997). In light of their potential benefits, CPA firms have begun to develop formal mentoring programs for accounting specialists to ensure that the advantages of mentoring are maintained rather than relying on happenstance (Siegel et al., 1997). The extant literature also addresses the benefits and shortcomings of formal mentoring programs for both auditing and tax professionals. (Viator, 2001; Siegel, et al., 1997; Herbohn, 2004). However, to date, no research addresses formal mentoring relative to management advisory services (MAS) professionals employed by CPA firms. MAS professionals work milieu is generally less structured than other professionals employed by CPA firms. In addition, they have greater operating autonomy than is usually the case in public accounting. Thus the purpose of this study is to compare the effects of formal and informal mentoring program effects on MAS professionals working at international public accounting firms. To evaluate the different mentoring programs, the study examines the mentoring processes within the tax departments of two international CPA firms that employ both formal and informal mentoring programs. The results indicate no significant differences between formal and informal programs on MAS professionals' career development. However, the statistical analysis did show a significant difference in the perceived influence of the programs at two professional levels on personal development that appears at the middle range of the programs. The results suggest that the informal mentoring approach leads to stronger personal relationships but does not extend to higher professional firm levels. Neither formal nor informal programs appear to have a significant influence to staff level professionals.
\end{abstract}

Keywords: Mentoring; Management Consultants; CPA firms

\section{INTRODUCTION}

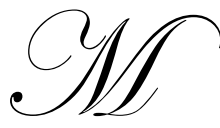

anagement advisory service (MAS) professionals encounter numerous challenges as they form professional identities and advance in their careers. This is especially true in large accounting firms where the reigning accounting oriented administrative style often clashes with the less structured and broader consulting style. MAS professionals are expected to interface with a wide range of clients and are constantly exposed to complex challenges and rapidly changing work assignments. Subsequently, MAS professionals must develop and maintain professional self-confidence in a stressful, demanding, and often adverse environment. MAS professionals may need role models who can provide guidance (Rigsby et al., 1998) and accelerate their professional development. Mentoring can provide assistance in fulfilling this need.

Numerous studies in the accounting literature report that mentoring can enhance work effectiveness and professional success (c. f. Viator \& Scandura, 1991; Siegel et al., 1995; Ibana, 2000; Klumman et al., 2002). 
However, the literature reports concerning which type of mentorship approach is more effective in achieving desired benefits have not been consistent. Some studies have found formal mentoring to be more advantageous for auditors in regional firms (Siegel \& Omer, 1995). However, Viator (2001) reports that informal mentoring provides better mentoring support functions than formally assigned mentors. Viator (1999) also found that formal programs that match lower level employees with upper level professionals are perceived as successful by the protégés.

\section{BACKGROUND}

\section{Formal \& Informal Programs}

Formal mentoring programs are those that are initiated through the assignment of mentor to protégé by the employer. This relationship is purported to facilitate and support developmental and professional career relationships within the assigned dyad for a certain period of time (Viator, 1999; Wanberg et al., 2003). Formal mentoring programs vary in structure in terms of mechanisms used matching protégés with mentors. At one end of the spectrum is the deliberate careful matching process and at the other end, a less structured match in which the dyad identify the unique needs they can fulfill for one another (Viator, 1999).

Formal relationships are structured with organizational assistance for a limited time period. The formal dyads can be circumscribed by a minimum number of meetings of a specified length and may also specify mentoring content requirements. Some programs require the parties to formally agree on all of the above-program length, frequency of meetings, and meeting content (Pollock, 1995).

Most of the mentoring research focuses on the benefits to the protégé of an informal relationship (Seigel et al., 2001; Viator \& Scandura, 1991, Herbohn, 2004; Scandura \& Viator, 1994). Informal mentoring relationships are a result of dyad interaction and are usually motivated by the needs of the two parties (Allen et al., 2005). These relationships will last as long as the dyad mentor/protégé remains involved with one another. However, as Kram (1983) notes, the dynamics and nature of the relationship changes over time. In addition, informal relationships are often less visible than their formal counterparts (Ragins \& Verbos, 2007).

\section{Benefits and Risks of Formal Mentoring Programs}

Enhanced socialization of new entrant to the profession has been identified as an important benefit of formal mentoring (Singh et al., 2002; Viator, 2001; Siegel et al., 1997). Mentoring enhances new accounting professionals by promoting greater adherence to the norms and standards of the profession. The formal mentoring program should result in individuals having better understanding of the CPA firms' missions, values, formal and informal structures. This improved socialization should lead to improved job performance, stronger organizational commitment, and lower turnover (Payne \& Huffman, 2005; Rigsby et al., 1998; Siegel et al., 1997; Viator, 1999).

Early identification of potential management and leadership development are also reported as benefits associated with formal mentoring programs (Siegel et al., 2002; Rigsby et al., 1998). If this is the case, instituting formal mentoring programs should result in faster promotion rates due to earlier professional development of employees' management aptitude and better firm planning on personnel utilization within the CPA firm (Viator, 2001; Siegel et al., 1997).

Studies show that formal mentoring programs can also have risks. Simon \& Eby (2003) suggest that formal mentoring may be prone to difficulties due to dysfunctional relational patterns stemming from dyad mismatches and technically or interpersonally inept mentors.

\section{Mentoring Functions}

The literature reports that mentoring serves two distinct functions, career-enhancing (career development) and psychosocial (personal) development (c.f. Kram, 1985; Scandura \& Siegel, 1995; Siegel et al., 2001). The career-enhancing function focuses on career advancement for entry-level employees as well as more senior professionals (Siegel et al., 1997; Allen et al., 2004). 
The psychosocial function involves support activities such as friendship and counseling. The psychosocial can enhance the individual's sense of identity as well as contribute to high levels of competence and self-evaluation (Burke, 1996; Siegel et al., 1997).

The career development function of mentoring can be conceptualized as those aspects of mentoring that enhance an individual's capability to learn the ropes and prepare for advancement in the CPA firm (Scandura \& Siegel, 1995; Herbohn, 2004). Career-enhancing functions can also involve political support through sponsoring and coaching, greater exposure and visibility, delivering challenging professionals assignments and protection if needed.

The psychosocial functions are conceptualized as role-modeling and individual development. Kram (1985) reports that role-modeling is the most significant reported psychosocial function that mentors provide for protégés. Siegel et al. (1997) also indicate that the psychosocial function assists protégés with social acceptance and perceived self- confidence and acceptance. The psychosocial function provides acceptance and confirmation of protégés as competent professionals, counseling them in times of adversity, and serving as role models when interfacing with firm culture as well.

\section{HYPOTHESES}

The preceding discussion of mentoring focuses on the benefits, risks, and structure types of mentoring. The accounting literature has studied auditors and tax professionals, but has not analyzed the role of mentoring for management advisory service (MAS) professionals. As noted above, the dynamics and complexity of the MAS environment is different than audit and tax areas. Therefore,

H1: formal systems provide more influence on career development than do informal systems

The accounting research reports that formal structures are perceived to be more effective at the first year of employment. The informal structures become more important as the professional gains more professional experience (Siegel et al., 1995; 1997). Subsequently,

H2: formal mentoring relationships provide more psychosocial benefits than do informal relationships

Prior studies report mixed results as to whether one system is different than the other (Viator, 2001; Chao et al., 1992).

\section{METHODOLOGY}

\section{Data}

The data was collected from local offices of international CPA firms located in the Southeastern United States. One firm had both formal and informal systems in place whereas the other neither had nor encouraged a mentorship program. The managing partners of each of the local offices were contacted and explained the purpose of the study. Subsequently, they agreed to participate.

The research instrument was distributed to the human resources department of each firm to administer to the personnel. Each firm received 125 questionnaires. The human resource personnel were requested to randomly select employees from varying professional levels within the MAS area.

The completed research instruments were collected by the human resource department and sent directly back to the researchers. The human resource personnel assured the individual participants that their survey responses would remain anonymous. Of the 250 questionnaires provided to the CPA firms, 180 were returned. Within the returned sample, two responses were incomplete leaving the usable sample at 178 for a response rate of $71.2 \%$. 
There were 83 responses from the firm that had no mentoring program compared with 95 for the mentoring program firm. Of the mentoring program, 44 respondents indicated they had a formal mentoring experience whereas 51 reported having informal. We controlled for participants who had both a formal and informal mentorship by requesting the firms to select only those candidates who reported either a formal or informal experience but not both. Table 1 provides a description of respondents by rank and firm type.

Table 1

Description of Respondents by rank \& type of firm mentoring

\begin{tabular}{|c|c|c|c|c|}
\hline Level & Formal & Informal & None & Total \\
\hline Staff & 11 & 13 & 26 & 50 \\
\hline Senior & 6 & 8 & 25 & 39 \\
\hline Manager & 20 & 27 & 27 & 74 \\
\hline Partner & 7 & 3 & 5 & 15 \\
\hline TOTALS & 44 & 51 & 83 & 178 \\
\hline
\end{tabular}

The largest category of participants in the study was at the managerial level. The responses are consistent with the distribution of professionals within large CPA firms (Rigsby et al., 1998). The participants were asked to indicate the type of mentoring relationships they had (formal or informal).

The participants were asked to record their perceptions of the influence of the mentor relationship on their career development using a 5-point Likert scale. The criteria for career development included their annual performance evaluation and promotion velocity. The scale was anchored by no influence and extraordinary influence.

Participants were then asked to indicate the influence of mentoring on their personal development (e.g. increased self-confidence and ability to make decisions). The same five-point scale was used as above.

\section{RESEARCH RESULTS}

Participants ranked the influence of the mentoring process on both career development and personal development. Other means and standards deviations for each professional level were calculated based on whether the participants were in the formal mentoring firm group, the informal mentorship firm group, or the non-mentoring firm group. Then, the responses were calculated for both career and personal (psychosocial) development. Table 2 shows the summary of means and standard deviations of the participants' responses.

The comparison was made of the reported mean influence between the formal and informal groups; between the formal and non mentoring group; and between the informal and non mentoring group. For the career development function of mentoring, the only significance was between the formal mentoring and non-mentoring at the partner level. The mean for formal was 3.36 compared to 4.40 for the non mentoring group.

The above result is contrary to prior research which reports significant influences of formal mentoring especially at the early career stages (staff and senior). However, it appears that mentoring whether formal or informal has just a marginal influence on the career development function of the protégés.

A statistical comparison was made of the reported influence between formal, informal and no mentoring programs using t-tests (see Tables 3 and 4 ).

At a p-value of .10 or less as significant, the only statistically significant mentoring effect on Career Development was with partners where no mentoring program was deemed to have more impact than formal. For Personal Development at the same p-value, senior and manager levels found informal mentoring had more impact than formal; managers also found no mentoring to be more impactful than formal programs where senior levels found informal mentoring more impactful than no mentoring program. 
Table 2

Summary of Participants Responses by Type of Mentoring

Career Development

Level

Staff

Senior

Manager

Partner

\begin{tabular}{|ccc|ccc|ccc|}
\hline & Formal & \multicolumn{3}{|c|}{ Informal } & \multicolumn{3}{c|}{ None } \\
\hline Mean & $\#$ & Std Dev. & Mean & $\#$ & Std Dev. & Mean & $\#$ & Std Dev. \\
\hline \hline 3.28 & 11 & 1.03 & 3.47 & 13 & 0.80 & 3.38 & 26 & 0.80 \\
3.37 & 6 & 0.96 & 3.58 & 8 & 0.74 & 3.56 & 25 & 0.77 \\
3.66 & 20 & 0.95 & 3.77 & 27 & 0.73 & 3.89 & 27 & 0.75 \\
3.36 & 7 & 0.94 & 3.67 & 3 & 0.75 & 4.40 & 5 & 0.89 \\
\hline
\end{tabular}

Personal Development

\begin{tabular}{l|c|c|c|c|c|c|c|c|c|}
\hline \multirow{2}{*}{ Level } & \multicolumn{3}{|c|}{ Formal } & \multicolumn{3}{c|}{ Informal } & \multicolumn{3}{c|}{ None } \\
\cline { 2 - 10 } & Mean & $\#$ & Std Dev. & Mean & $\#$ & Std Dev. & Mean & \# & Std Dev. \\
\cline { 2 - 10 } & 3.18 & 11 & 1.00 & 3.50 & 13 & 0.82 & 3.19 & 26 & 0.94 \\
Senior & 3.23 & 6 & 0.86 & 3.98 & 8 & 0.76 & 3.52 & 25 & 0.77 \\
Manager & 3.43 & 20 & 0.94 & 3.79 & 27 & 0.70 & 4.00 & 27 & 0.78 \\
Partner & 3.37 & 7 & 0.95 & 3.67 & 3 & 0.73 & 4.25 & 5 & 0.96 \\
\hline
\end{tabular}

Table 3

Statistical Conclusions for Career Development Effect

\begin{tabular}{|c|c|c|c|c|c|c|}
\hline \multirow[t]{2}{*}{ Level } & \multicolumn{2}{|c|}{ Formal Vs Informal } & \multicolumn{2}{|c|}{ Formal Vs None } & \multicolumn{2}{|c|}{ Informal Vs None } \\
\hline & tstat & p-value & tstat & $p$-value & tstat & $p$-value \\
\hline Staff & -0.5087 & 0.3080 & -0.3326 & 0.3707 & 0.3132 & 0.3785 \\
\hline Senior & -0.4636 & 0.3256 & -0.5195 & 0.3035 & 0.0646 & 0.4745 \\
\hline Manager & -0.4492 & 0.3277 & -0.9227 & 0.1802 & -0.5898 & 0.2804 \\
\hline Partner & -0.5012 & 0.3149 & -1.9263 & $0.0512 *$ & -1.1774 & 0.1801 \\
\hline
\end{tabular}

$*$ Significant at the .10 level of confidence

Table 4

Statistical Conclusions for Personal Development Effect

\begin{tabular}{|c|c|c|c|c|c|c|}
\hline \multirow[t]{2}{*}{ Level } & \multicolumn{2}{|c|}{ Formal Vs Informal } & \multicolumn{2}{|c|}{ Formal Vs None } & \multicolumn{2}{|c|}{ Informal Vs None } \\
\hline & tstat & p-value & tstat & p-value & tstat & p-value \\
\hline Staff & -0.8619 & 0.1990 & -0.0358 & 0.4858 & 1.0042 & 0.1629 \\
\hline Senior & -1.7290 & $0.0547 *$ & -0.8111 & 0.2117 & 1.4746 & $0.0776 *$ \\
\hline Manager & -1.5064 & $0.0695 *$ & -2.2634 & $0.0139 *$ & -1.0379 & 0.1551 \\
\hline Partner & -0.4830 & 0.3210 & -1.4740 & 0.1002 & -0.8693 & 0.2722 \\
\hline
\end{tabular}

*Significant at the .10 level of confidence

\section{DISCUSSION AND CONCLUSION}

The data were obtained from international (large) CPA firms located in different metropolitan areas of the southeastern sector of the Unites States. The participants represented several professional levels within the firm regarding the influence of mentoring relationships for career and personal development functions of MAS professionals.

The statistical results indicate that for MAS professionals, informal mentoring play a larger influence on the participants' perception of the mentoring process. However, the results were only significant at the partner level. These results are similar to those reported for tax professionals (Siegel et al., 1997). However, other studies of auditors (Viator, 2001; Scandura \& Siegel, 1995; Siegel \& Reinstein, 2001) report that both formal and informal mentoring have a significant influence on individual career development at early career levels such as staff or senior. 
The study also reports that informal mentoring has greater influence at the more senior levels in the CPA firms for personal development. These results are once again similar to those reported for tax professionals (Siegel et al., 1997). However, the mentoring literature found that the psychosocial function to be more pronounced at the lower professional levels and to be more closely associated with formal mentoring (Chao et al., 1992; Allen et al., 2005; Siegel \& Reinstein, 2001.)

The current study suggests that both formal and informal mentoring programs as well as non mentoring program approaches appear to have some influence on MAS professionals. However, this influence was primarily reported at the senior levels of the CPA firms. The study participants responded that the psychosocial function of mentoring is more significant than the career development function.

The MAS environment is generally different than other areas within the public accounting firm such as tax and auditing. The MAS area has been characterized as stressful and rapidly changing (Rigsby et al., 1998). Informal mentoring and non mentoring structures are perceived as having greater influence on MAS professionals than formal. This implies that CPA firms should encourage the formation of informal mentoring relationships.

It appears that MAS professionals prefer to let the mentoring process evolve naturally and to select their own mentors and protégés (c.f. Scandura \& Siegel, 1995). CPA firms might want to review their formal organizational practices and program features that facilitate formal programs to provide benefits similar to those of informal programs.

It should also be noted that different organizational cultures will affect whether the results can be generalized. Another limitation for the study was firm size. Some studies indicate that the impact of mentoring will be different for local or regional firms (Herbohn, 2004. Similarly, the national culture of the country in which the CPA firm operates has an impact on mentoring experiences (Herbohn, 2004.)

Future research should study and compare firms with varying cultures within each mentoring approach. Further, as global firm activity increases, the impact of international mentoring should be studied. Finally, future research if possible should compare the perceived benefits of the different systems over time. The research could compare the perceived benefits of different systems over a MAS professional's career.

\section{AUTHOR INFORMATION}

Philip H. Siegel is presently the Peter S. Knox Distinguished Chair of Accounting at the Hull College of Business, Augusta State University. He received his PH.D. in accounting from the University of Memphis and is a CPA (active, state of Florida). His research has been published in the Journal of Accounting, Auditing, and Finance: Journal of the American Taxation Association; Review of Quantitative Finance and Accounting; Advances in Accounting; Journal of Business Ethics and other peer reviewed journals.

Todd Schultz is a professor of Information \& Decision Technologies at Augusta State University. His academic background includes a doctorate in operations research -- or analytics in today's vernacular -- but his research interests and practical experience of over 30 years is in quantitative programming, business software, database, and business intelligence as an independent consultant and with firms such as American Management Systems and Ernst \& Young Management Consulting Services.

Sharon D. Landy, currently a graduate student in the Hull School of Business MBA program at Augusta State University. She earned her Bachelor's of Science Degree with Honors in Business Administration from the University of South Carolina Aiken.

\section{REFERENCES}

1. Allen, T. D., Eby, L., Poteet, M., \& Lentz, E. (2006). "Career Benefits Associated with Mentoring for Protégé: A Meta Analysis,” Journal of Applied Psychology 90, pp. 127-136. 
2. Allen, T. D. \& R. Day \& E. Lentz (2006). "The Role of Interpersonal Comfort in Mentoring Relationships," Journal of Career Development," (31) pp. 155-169.

3. Burke, R. J. (1996). "Performance Evaluation \& Counseling in a Professional Service Firm," Leadership \& Organization Development, 17(3) pp. 21-26.

4. Chao, G. T., Walz, P. \& P. Gardner (1992). "Formal \& Informal Mentorships: A Comparison on Mentoring Functions \& Contrast with Nonmentored Counterparts," Personnel Psychology, 45(3) pp. 613-636.

5. Herbohn, K. (2004). "Informal Mentoring Relationships and the Career Processes of Public Accountants," British Accounting Review 36(4) pp. 369-393.

6. Keller, R. (2000). "Make the Most of Mentoring," Journal of Accountancy 206(2); pp. 76-80.

7. Kram, K. (1983). "Phases of the Mentoring Relationships," Academy of Management Journal 26 pp. $608-$ 625.

8. Kram, K. A. (1985). “Mentoring at Work: Developmental Relationships in Organizational Life. Glenview, IL: Scott, Foresman.

9. Payne, S. C. \& A. H. Huffman (2008). "A Longitudinal Examination of the Influence of Mentoring on Organizational Commitment \& Turnover.” Academy of Management Journal 48, pp. 158-168.

10. Pollock, R. (1995). "A Test of Conceptual Models Depicting the Developmental Course of Informal Mentor-Protégé Relationships in the Workplace.” Journal of Vocational Behavior, 46; pp. 144-162.

11. Ragins, B. \& Verbos, V. (2007). "Positive Relationships in Action: Relational Mentoring \& Mentoring Schemes in the Workplace," In J. E. Dutton \& B. R. Ragins (ed.), Exploring Positive Relationships at Work. Building a Theoretical and Research Foundation, pp. 91-116; Mahwak, NJ; Laurirce Erlbaum.

12. Rigsby, J. T. \& P. H. Siegel, \& J. D. Spiceland (1998). "Mentoring Among Management Advisory Services Professionals: An Adaptive Mechanism to Cope with Rapid Corporate Change," Managerial Auditing Journal 13(2) pp. 107-116.

13. Scandura, T. A. \& P. H. Siegel (1995). "Mentoring as Organization Learning During a Corporate Merger." Paper presented at the 1995 National Academy of Management Meeting, Vancouver, Canada.

14. Scandura, T. A. \& R. E. Viator. (1994). "Mentoring in Public Accounting Firms: Analysis of MentorProtégé Relationships, Mentorships, Functions \& Protégé Turnover Intentions," Accounting, Organizations \& Society 19(8); pp. 717-734.

15. Siegel, P. H. \& A. Reinstein. (2001). “An Exploratory Study of Mentor Relationships in Large CPA Firms," Scandinavian Journal of Management, 17(4); pp. 421-436.

16. \& J. Smith \& J. Mosca. (2001). "Mentoring Relationships and Interpersonal Orientation." The Leadership \& Organizational Development Journal, 22(3) pp. 114-126.

17. \& K. Omer (1995). "Mentoring as an Antidote to Stress During a Regional CPA Firm Merger," Journal of Business \& Entreprenuership 7(1) pp. 87-100.

18. \& R. W. Rultedge, \& J. M. Hagan, (1997). "The Mentor Relationship Within the Public Accounting Firm: It's Impact on Tax Professional Performance," Advances in Taxation 9(1); pp. 175-199.

19. Simon, S. A. \& L. T. Eby (2003). "A Typology of Negative Mentoring Experience: A Multidimensional Scaling Study," Human Relations 56(9) pp. 1083-1106.

20. Singh, V., D. Bains \& S. Vissnicombe, (2002). "Informal Mentoring as an Organizational Resource." Long Range Planning, (135) pp. 389-405.

21. Viator, R. (2001). "The Association of Formal \& Informal Public Accounting Mentoring with Role Stress and Related Job Outcomes," Accounting, Organization, \& Society 26(1), pp. 73-93.

22. Viator, R. \& T. Scandura (1991). "A Study of Mentor-Protégé Relationships in Large

23. Wanberg, C. R., E. T. Welsh, \& S. A. Hozlett. (2003). "Mentoring Research: A Review \& Dynamic Process Model," Research In Personnel \& Human Resources Management 22, pp. 39-124. 


\section{NOTES}

